\title{
Human tonsillar tissue block cultures differ from autologous tonsillar cell suspension cultures in lymphocyte subset activation and cytokine gene expression
}

\author{
Bettina Giger $^{\mathrm{a}}$, Athos Bonanomi ${ }^{\mathrm{a}}$, Bernhard Odermatt ${ }^{\mathrm{b}}$, Kristin Ladell ${ }^{\mathrm{a}}$, \\ Roberto F. Speck ${ }^{\mathrm{c}}$, Dejan Kojic ${ }^{\mathrm{a}}$, Christoph Berger ${ }^{\mathrm{a}}$, Felix K. Niggli ${ }^{\mathrm{d}}$, David Nadal ${ }^{\mathrm{a}, *}$ \\ ${ }^{a}$ Division of Infectious Diseases, University Children's Hospital of Zurich, Steinwiesstrasse 75, CH-8032 Zurich, Switzerland \\ ${ }^{\mathrm{b}}$ Department of Pathology, University Hospital of Zurich, Zurich, Switzerland \\ ${ }^{\mathrm{c}}$ Division of Infectious Diseases and Hospital Hygiene, Department of Internal Medicine, \\ University Children's Hospital of Zurich, Zurich, Switzerland \\ ${ }^{\mathrm{d}}$ Division of Oncology, University Children's Hospital of Zurich, Zurich, Switzerland
}

Received 13 October 2003; received in revised form 29 March 2004; accepted 19 April 2004

Available online 31 May 2004

\begin{abstract}
Lymphoid tissues cultured either as tissue blocks or as cell suspensions are used to study the behaviour of immune cells within their habitat. The preservation of tissue structures in tissue blocks, which is considered to be a major advantage, has been poorly defined. We characterised the morphological evolution of tissue cultures from human palatine tonsils and compared their lymphocyte subsets and the constitutive cytokine gene expression to those in autologous tonsillar single-cell suspension cultures over time, and after adding cyclosporin A (CsA) to mimic the situation in individuals treated with immunosuppressive drugs. Density and morphology of follicles were conserved up to 4 days, during which tissue cultures exhibited similar cell viability as suspension cultures, but a significantly less frequent increase of CD95 expression in T cells, smaller variation of the proportion of $\mathrm{CD}^{+}$cells and better $\mathrm{CD} 21^{+} / \mathrm{CD} 23^{-}$B-cell survival. Treatment with cyclosporin A at higher concentrations resulted in superior histologic preservation of lymphoid tissue structures and seemed to further prevent the expression of CD95 by $\mathrm{CD} 3^{+}$ cells and the activation in tissue culture of $\mathrm{CD} 21^{+}$cells. Constitutive gene expression levels of the stromal cytokines interleukin (IL)- $1 \beta$ and interleukin- 6 in tissue culture were significantly higher than those in suspension cultures. These results suggest that tonsillar tissue cultures preserve their structure only for a limited time, during which they more closely reflect processes in vivo, including a state of iatrogenic immunosuppression, than do their cell suspension counterparts.
\end{abstract}

(C) 2004 Elsevier B.V. All rights reserved.

Keywords: Tonsillar tissue block cultures; Cell suspension cultures; In vitro model; Cytokines; Lymphocyte subsets; Cyclosporin A; Interleukin1; Interleukin-6; Transforming growth factor- $\beta$

Abbreviations: CsA, cyclosporin A; FITC, fluorescein isothiocyanate; HE, haematoxylin-eosin; IFN, interferon; IL, interleukin; TCSC, tonsillar cell suspension culture; TGF, transforming growth factor; TTBC, tonsillar tissue block culture; PE, phycoerythrin.

* Corresponding author. Tel.: +41-1-266-7562; fax: +41-1-266-7157.

E-mail address: david.nadal@kispi.unizh.ch (D. Nadal). 


\section{Introduction}

Immune responses, such as activation or differentiation of B lymphocytes in germinal centres, are tightly regulated by signals from different interacting cell populations (Abbas and Lichtman, 2003). Cultures of cell suspensions, often used to mimic in vivo situations, probably reflect the situation in vivo only to a limited degree since they lack tissue structures essential for the development of immune responses. This drawback, i.e., the likelihood of missing important steps, could be overcome by culturing lymphoid tissue blocks that preserve organ tissue structure thereby retaining the original microenvironment, as reported for cultures using tissue samples from spleen, cervix or tumours (Hoffmann et al., 1995; Collins et al., 2000; Au et al., 2002).

The survival of cells in tissue cultures from spleen is comparable to counterparts cultured in single-cell suspensions (Hoffmann et al., 1995). Immunoglobulin production in these tissue cultures starts more promptly and reaches higher levels than in cell suspension cultures (Hoffmann et al., 1995). Moreover, marked differences in the cytokine secretion profile between tissue cultures and cell suspension cultures have been observed (Skibinski et al., 1997; Skibinski and James, 1997).

Tonsils are candidate organs for tissue culture since they are more readily obtainable than spleen or other secondary lymphoid organs. Tissue cultures from human palatine tonsils have been employed to study lymphocyte activation and differentiation (Ferro et al., 1993) and immune processes during infection with the human immunodeficiency virus (Glushakova et al., 1995; Blauvelt et al., 2000; Grivel et al., 2001; Penn et al., 2001; Bounou et al., 2002) and the human herpesvirus 6 (Grivel et al., 2001, 2003). However, the morphological evolution of these tissue cultures has been characterised to only a limited degree.

This work aimed to describe the evolution of tissue structures in tonsillar tissue block cultures (TTBCs) and compare lymphocyte subsets in TTBCs with those in autologous tonsillar cell suspension cultures (TCSCs) over time. Furthermore, by adding cyclosporin A (CsA) to the cultures, the situation in individuals treated with immunosuppressive drugs could be mimicked. Since the cytokine milieu in vivo results from the interaction of many different cells within the microenvironment of preserved tissue structure, we also examined the expression of cytokine genes in TTBCs versus TCSCs.

\section{Materials and methods}

\subsection{Tissue samples}

The palatine tonsils which were used were surgically removed from children because of hyperplasia at the University Children's Hospital of Zurich. The organs were immediately wrapped in sterile gauze soaked with phosphate-buffered saline pH 7.4 (Invitrogen, Basel, Switzerland), placed in a sterile airtight container and transported to the laboratory within $4 \mathrm{~h}$. The institutional ethics committee approved the study.

\subsection{Preparation of tonsillar tissue block and cell suspension cultures}

From each tonsil, TTBCs and TCSCs were prepared in parallel. For TTBCs, part of the tonsil was cut manually in phosphate-buffered saline into $2-\mathrm{mm}^{3}$ blocks that were set up in sponge cultures (Jenkinson et al., 1982) as follows: each well of a 6-well plate contained a gelatine sponge (Gelfoam, $1 \mathrm{~cm}$ thick, Pharmacia \& Upjohn, Dübendorf, Switzerland) soaked with medium and covered with a membrane (Isopore, $4 \mu \mathrm{m}$, Millipore, Volketswil, Switzerland). On each membrane, six tissue blocks were placed and medium was added to reach the level of the membrane. For TCSCs, the other part of the tonsil was disintegrated with a scalpel tip in fresh medium and filtered through a $70-\mu \mathrm{m}$ cell strainer (Falcon, Fisher, Wohlen, Switzerland). Cells were counted using the $0.4 \%$ trypan blue (Sigma, Buchs, Switzerland) exclusion test and cultured in 24-well plates, each well containing $2 \times 10^{6}$ viable cells in $1-\mathrm{ml}$ medium. Both TTBCs and TCSCs were kept in a humidified incubator at $37{ }^{\circ} \mathrm{C}$ and $5 \% \mathrm{CO}_{2}$. Every second day, half of the medium was replaced.

\subsection{Culture media and treatments}

TTBCs were set up with Yssel's medium (Gemini Bio-Products, Woodland, CA, USA) and RPMI 1640 medium (Invitrogen), and the latter was used also for 
TCSCs. Both media contained HEPES buffer, L-glutamine, $1 \mathrm{mM}$ sodium pyruvate, $1 \mathrm{mM}$ nonessential amino acids, $15 \%$ fetal bovine serum, $100 \mathrm{U} / \mathrm{ml}$ penicillin, $100 \mu \mathrm{g} / \mathrm{ml}$ streptomycin sulfate and 2.5 $\mu \mathrm{g} / \mathrm{ml}$ amphotericin B (all from Invitrogen). For some experiments, 1,5 or $25 \mathrm{mg} / 1$ CsA (Novartis, Basel, Switzerland) was added. All cultures for each condition were set up at least in duplicate.

\subsection{Assessment of tissue structure preservation in tonsillar tissue block cultures}

Tissue blocks were harvested daily until day 8 , fixed in 4\% buffered formalin (Sigma), embedded in Paraplast, sectioned and stained in haematoxylineosin (HE) solution (Fluka, Buchs, Switzerland). Density and morphology of lymphoid follicles, tissue consistency and necrosis were rated using the scale listed in Table 1.

\subsection{Immunohistochemical phenotyping of lymphocyte subsets}

Immunohistochemistry was performed on paraffin sections from tissues using the Ventana Benchmark automated staining system (Ventana Medical Systems,

Table 1

Histological rating criteria for tonsillar tissue block cultures

\begin{tabular}{ll}
\hline Parameter & Score \\
\hline $\begin{array}{l}\text { Lymphoid follicles: density and morphology } \\
\text { High density }\end{array}$ & 4 \\
$\quad$ (more than 5 per low power optical field) & 3 \\
High density, loss of thickness of the follicle & \\
$\quad$ wall & 2 \\
Low density (1-3), only small number of & \\
$\quad$ follicles & 1 \\
No lymphoid follicles & \\
& \\
Tissue consistency & 4 \\
Compact throughout the tissue & 3 \\
Tissue loosening in the germinal centres & 2 \\
Tissue loosening throughout the section & 1 \\
Several small dissolved spots, mainly in & \\
the centre of the tissue & \\
Necrosis & \\
$<20 \%$ of tissue area & 4 \\
$20-40 \%$ & 3 \\
$>40-60 \%$ & 2 \\
$>60 \%$ & 1 \\
\hline
\end{tabular}

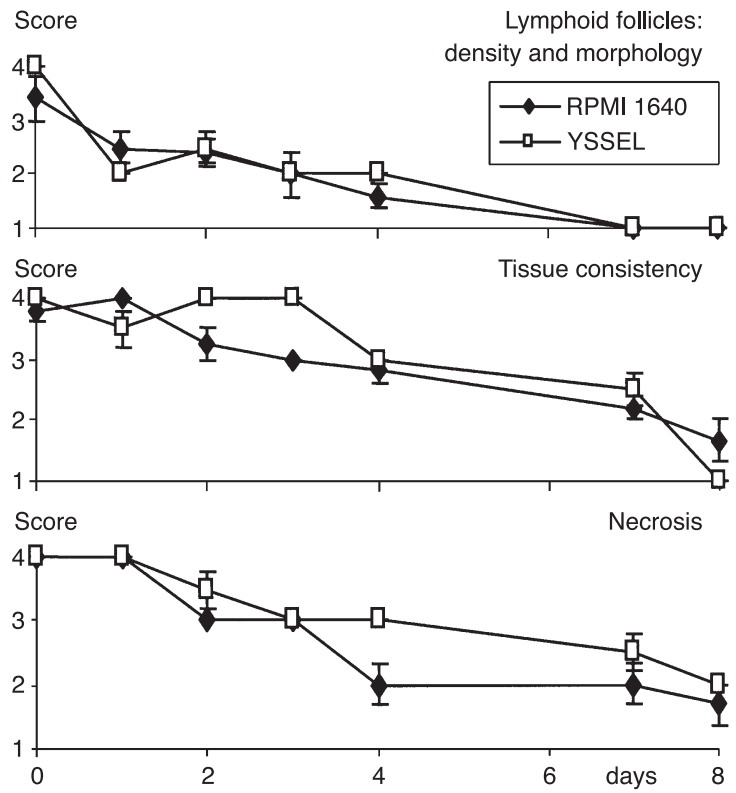

Fig. 1. Rating of morphological evolution of TTBCs over time. Tissue blocks of the same tonsil were cultured in RPMI 1640 or Yssel's medium. The rating scale presented in Table 1 was applied to sections of TTBCs from eight organs. The evolution of the average score with standard error bars for 8 days comparing the two media is shown.

Tucson, AZ, USA). For antigen retrieval, slides were heated with cell conditioner 1 (mild protocol). For CD68, enzymatic predigestion with protease 1 was performed for $2 \mathrm{~min}$. Primary antibodies against the following antigens were applied: CD3 (affinity purified rabbit antibodies, dilution 1/80; DakoCytomation, Glostrup, Denmark), CD4 (clone 1F6, dilution 1/10; Novocastra, Newcastle upon Tyne, UK), CD8 (clone C8/144B, dilution 1/100; Dako, Zug, Switzerland), CD20 (clone L26, dilution 1/400; Dako), CD23 (clone 1B12, dilution 1/30; Novocastra) and CD68 (clone PG-M1, dilution 1/50; Dako). Primary antibodies were detected with the Ventana iVIEW DAB detection kit, yielding a brown reaction product. For CD4, CD8 and CD23, the signal was enhanced with the Ventana amplification kit. Slides were counterstained with haematoxylin. 2.6. Assessment of cell viability and relative distribu-
tion of lymphocyte subsets

Tissue blocks were disintegrated with a scalpel tip in staining buffer (phosphate-buffered saline with 5\% 


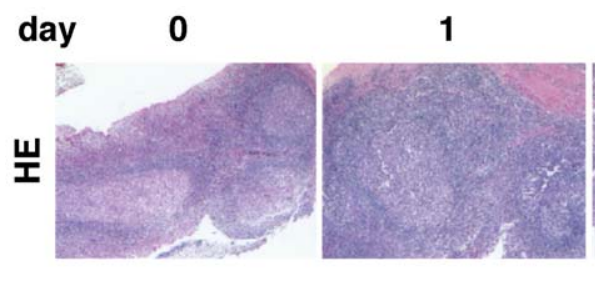

2

3

4

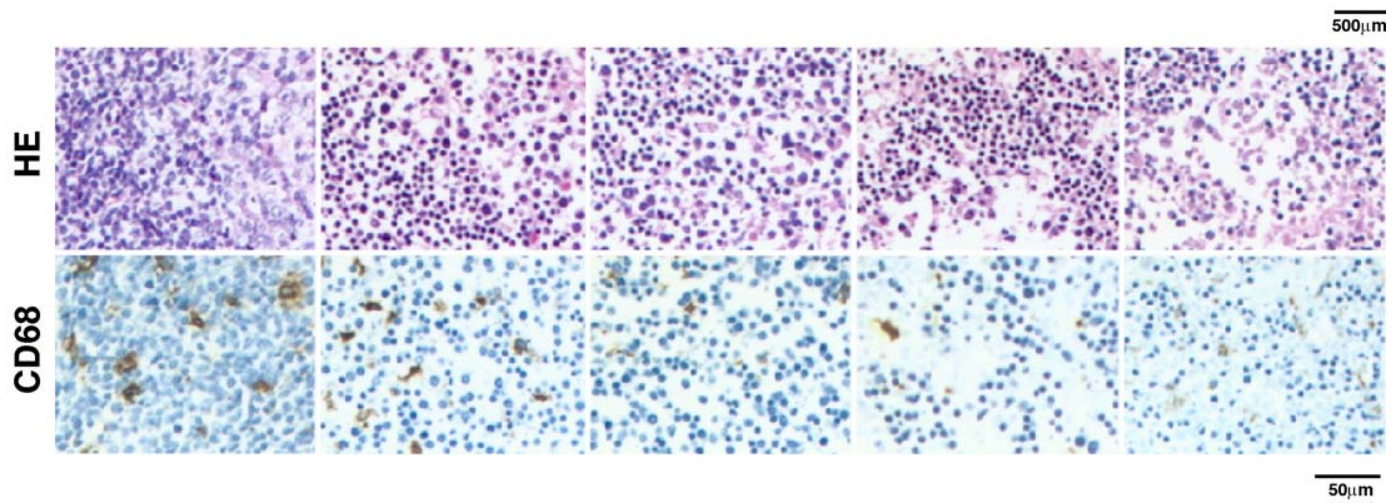

Fig. 2. Representative paraffin sections of TTBCs at days $0,1,2,3$ and 4 of culture, respectively. HE-stained sections are shown at two different magnifications. Sections immunostained for the macrophage marker CD68 are shown at the higher magnification. Note involution of the follicular structure, loosening of the cell aggregation density and decrease of number and size of the macrophages (CD68 ${ }^{+}$cells) over time.

fetal bovine serum and $0.1 \%$ sodium azide; Sigma) and filtered through a $70-\mu \mathrm{m}$ cell strainer (Falcon) to obtain single-cell suspensions. Pellets of TCSCs were resuspended and washed with staining buffer. Single cells $\left(2.5 \times 10^{5}\right)$ were double-stained with a fluorescein isothiocyanate (FITC)-labelled and a phycoerythrin (PE)-labelled mouse monoclonal antibodies (all from BD Biosciences, Basel, Switzerland, if not stated differently) at a dilution of $1 / 10$, for $30 \mathrm{~min}$ at $4{ }^{\circ} \mathrm{C}$ in the dark following the instructions of the manufacturer. FITC-conjugated anti-mouse IgG1 (FITC-IgG1) with PE-conjugated anti-mouse IgG1 (PE-IgG1), FITC-IgG1 with PE-HLA-ABC and FITC-CD45 with PE-IgG1 served as isotype controls. 7-Aminoactinomycin D (7-AAD) was used to identify nonviable cells. B cells versus $T$ cells were quantified by FITC-CD20 with PE-CD3. Activated cells prone to apoptosis were monitored by FITC-CD95 with PECD3 or with PE-CD20, respectively. T helper lymphocytes versus cytotoxic $\mathrm{T}$ lymphocytes were distinguished with FITC-CD4 and PE-CD8. Resting and activated $\mathrm{B}$ cells were identified using FITC-CD21 (Dako) with PE-CD23. After staining, the cells were washed with staining buffer, fixed with $3 \%$ parafor- maldehyde for 20 min and washed again. The percentages of positive cells and mean fluorescence intensity were analysed using FACS Calibur (BD Biosciences) equipped with a 488- and 635-nm laser for double-

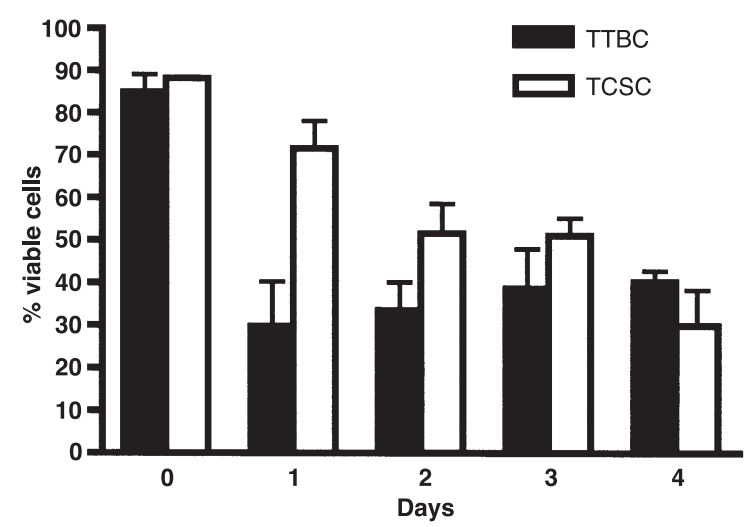

Fig. 3. Cell viability in tonsillar tissue block cultures (TTBCs) and tonsillar cell suspension cultures (TCSCs). Cells from four replicate cultures were stained with 7-amino-actinomycin D (7-AAD) to quantify nonviable cells by FACS and therefore to determine the cell survival shortly after excision and during 4 days in culture. The data are presented as average percentages of viable cells for autologous TTBCs and TCSCs with standard deviation. 
colour analysis, gating on the lymphocyte population, as defined by forward and side light scatter. Data were recorded and analysed with Cell Quest software (BD Biosciences).

\subsection{Assessment of cytokine gene expression}

RNA extractions and real-time quantitative polymerase chain reactions (PCRs; TaqMan ${ }^{\mathrm{TM}}$ ) for human interleukin (IL)-1 $\beta$, IL-2, IL-6, IL-10, IL-12, IL-15, interferon (IFN)- $\gamma$, transforming growth factor (TGF)$\beta$ and the endogenous reference, the housekeeping gene hydroxymethylbilane synthase, were performed following the supplier's instructions (Applied Biosystems, Foster City, CA, USA) and as described previously (Bonanomi et al., 2003). All reactions were performed in duplicate.

\subsection{Statistics}

For comparison between groups, either the $\chi^{2}$ test or the two-tailed Fisher's exact test was used. The Mann-Whitney $U$-test was used for comparison of mean \pm standard errors of the mean values between groups. Values of $p<0.05$ were considered statistically significant.
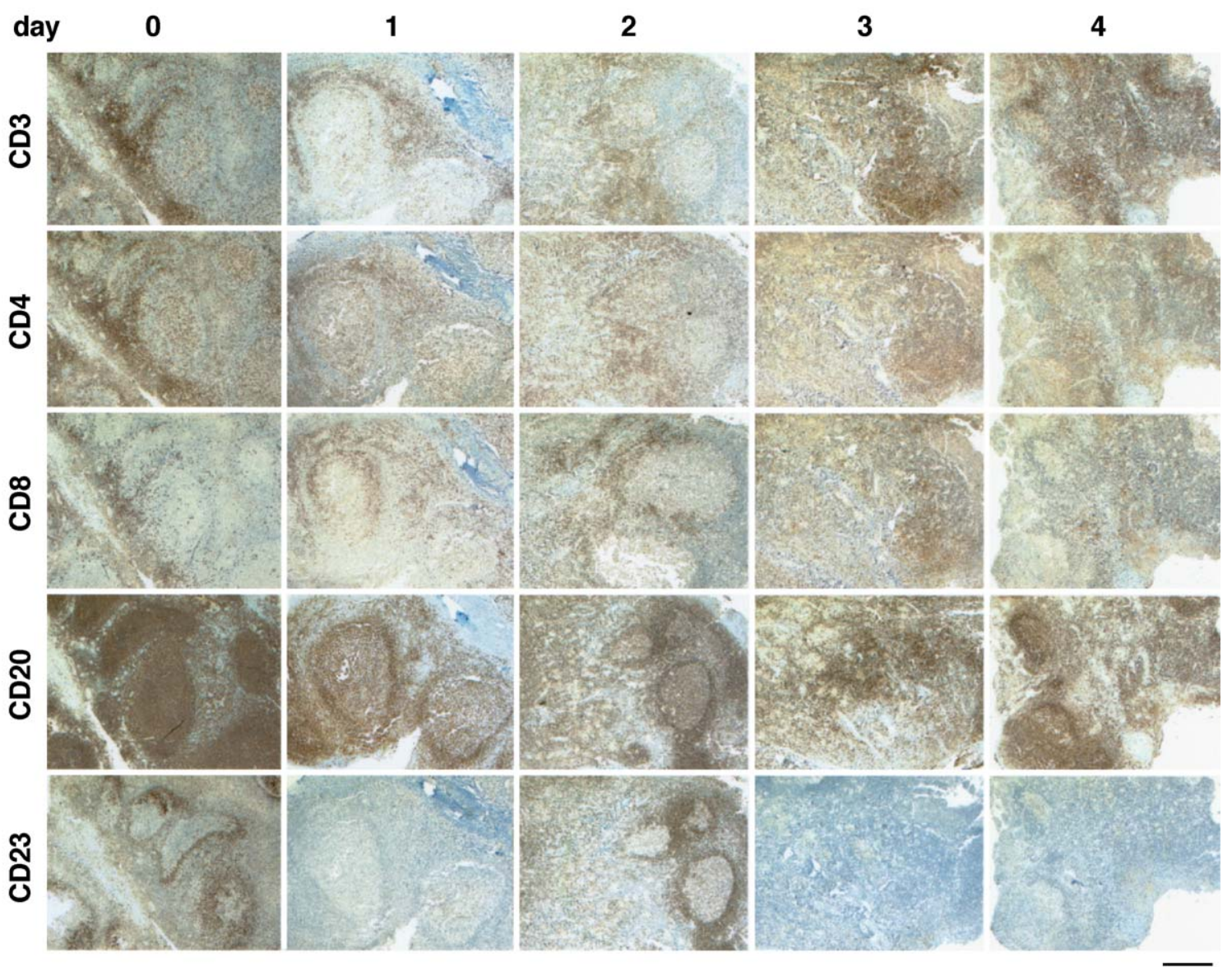

$\overline{500 \mu \mathrm{m}}$

Fig. 4. In situ localisation of lymphocyte subsets in TTBCs over time. At each day in culture, paraffin sections from a single tissue block cultured in RPMI 1640 medium were stained with antibodies against the T cell markers CD3, CD4 and CD8, the B cell markers CD20 and CD23 or the macrophage marker CD68. 


\section{Results}

\subsection{Morphological evolution of TTBCS}

The number and morphology of follicles over time were similar in Yssel's medium and RPMI 1640 medium, showing a decrease from day 1 to day 7 when all follicles had disappeared (Fig. 1). The preservation of the tissue consistency differed slightly between both media in the first 3 days in favour of Yssel's medium, but was similar thereafter. Necrosis was augmented more rapidly after day 3 using RPMI 1640 medium compared to Yssel's medium. However, the sponges used to support the TTBCs disintegrated in Yssel's medium but not in RPMI 1640 medium and impeded preparation of tissue sections after day 3. Thus, based on the morphological rating, both RPMI 1640 medium and Yssel's medium can be used to establish TTBCs, but due to structural changes of the tissue, including involution of the follicular structure, loosening of the cell aggregation density and a decrease in the number and size of the macrophages over time (Fig. 2), potential functional advantages of TTBCs over TCSCs could only be expected within the first 4 days of culture. Therefore, we limited cultures to 4 days and preferred RPMI 1640 medium to Yssel's medium for the better preservation of the sponges and better comparison with TCSCs.

\subsection{Cell viability and lymphocyte subsets}

Staining with 7-AAD showed that in both TTBCs and in TCSCs, the viability of gated lymphocytes was comparable on days $0(84.9 \pm 4.1 \%$ versus $88.1 \pm 0.4 \%), 3$ and 4 of culture, when it declined to $38.6 \pm 2.5 \%$ versus $29.9 \pm 8.3 \%$. However, viability was lower in TTBCs than that of TCSCs on days 1 and 2 (Fig. 3).

Immunohistochemical staining of TTBC tissue sections from day 0 (Fig. 4) showed typical welldemarcated secondary follicles with well-developed germinal centres. Follicle mantle zones and germinal centres stained for CD20. Cells within the follicular mantle zone also expressed CD23, although the most prominent staining for this marker was seen on follicular dendritic cells in the apical light zones of germinal centres. $\mathrm{CD}^{+}$cells (mostly $\mathrm{CD}^{+}$and, to a lesser extent, $\mathrm{CD} 8^{+}$) localised preferentially in the $\mathrm{T}$ zones. Numerous macrophages expressing CD68 were found in germinal centres and scattered in the surrounding areas. This regular distribution of the different cell subsets lasted until day 4 in TTBCs. However, immunostaining started to fade on days 3 and 4 (Fig. 4) and became completely diffused thereafter (not shown), reflecting the decay of tissue structure observed in HE-stained sections.

Table 2 and Fig. 5 show the variations in lymphocyte subsets in TTBCs and TCSCs on day 4 of culture compared to the frequencies on day 0 . The proportion of $\mathrm{CD}^{+} / \mathrm{CD} 95^{-}$cells increased in TTBCs and TCSCs, whereas the proportion of $\mathrm{CD} 20^{+}$cells decreased. The differences between TTBCs and autologous TCSCs were within the $10 \%$ range, except for two pairs with $\mathrm{CD}^{+} / \mathrm{CD}^{-} 5^{-}$cells in TTBCs higher by $17.2 \%$ and $36.8 \%$, respectively, than in TCSCs (Fig. 5). Only 2 out of 12 TTBCs, but 11 out of 12 TCSCs showed an increase of $\mathrm{CD}^{+} / \mathrm{CD}^{+} 5^{+}$cells (Fig. $5 ; p<0.001$ ). Accordingly, the average change of $\mathrm{CD}^{+} / \mathrm{CD}^{+} 5^{+}$cells compared to baseline in TTBCs was lower than that of TCSCs $(p=0.019)$. The variation of the relative $\mathrm{CD}^{+}$cell increase in TTBCs was smaller than that of TCSCs (Table 2). In three $(25 \%)$ TCSCs, a relative increase of the $\mathrm{CD}^{+}$cell percentage greater than $20 \%$ compared to baseline was observed. These three TCSCs and a fourth one showed $\mathrm{CD}^{+}$cell percentages between $14.6 \%$ and $25.5 \%$ greater than autologous TTBCs. Finally, an increase in the percentage of resting, mature $\mathrm{B}$ cells $\left(\mathrm{CD} 21^{+} / \mathrm{CD} 23^{-}\right)$was noted in four TTBCs and one

Table 2

Relative distribution of lymphocyte subsets in tonsillar tissue block cultures and tonsillar cell suspension cultures on day 4 compared to day 0

\begin{tabular}{lccl}
\hline Phenotype & \multicolumn{2}{l}{ Variation } & \multirow{2}{*}{$p$ Values } \\
\cline { 2 - 3 } & \multicolumn{1}{c}{ TTBC } & \multicolumn{1}{c}{ TCSC } & \\
\hline $\mathrm{CD}^{+} / \mathrm{CD}^{-} 5^{-}$ & $23.47 \pm 6.67$ & $17.21 \pm 7.38$ & $\mathrm{~ns}$ \\
$\mathrm{CD}^{+} / \mathrm{CD} 5^{+}$ & $-1.3 \pm 1.6$ & $4.5 \pm 1.9$ & 0.019 \\
$\mathrm{CD}^{+} / \mathrm{CD} 8^{-}$ & $2.9 \pm 2.1$ & $6.4 \pm 5.0$ & $\mathrm{~ns}$ \\
$\mathrm{CD}^{-} / \mathrm{CD} 8^{+}$ & $5.6 \pm 0.7$ & $3.8 \pm 1.3$ & $\mathrm{~ns}$ \\
$\mathrm{CD} 20^{+} / \mathrm{CD} 95^{-}$ & $-21.0 \pm 8.7$ & $-14.8 \pm 7.4$ & $\mathrm{~ns}$ \\
$\mathrm{CD} 20^{+} / \mathrm{CD} 95^{+}$ & $-5.9 \pm 2.2$ & $-4.7 \pm 3.1$ & $\mathrm{~ns}$ \\
$\mathrm{CD} 21^{+} / \mathrm{CD} 23^{-}$ & $-2.7 \pm 4.9$ & $-8.8 \pm 2.6$ & $\mathrm{~ns}$ \\
$\mathrm{CD} 21^{+} / \mathrm{CD} 23^{+}$ & $-28.0 \pm 5.1$ & $-22.4 \pm 6.8$ & $\mathrm{~ns}$ \\
\hline
\end{tabular}

Values are presented as means \pm S.E.M. of 12 tonsils; ns: not significant. 


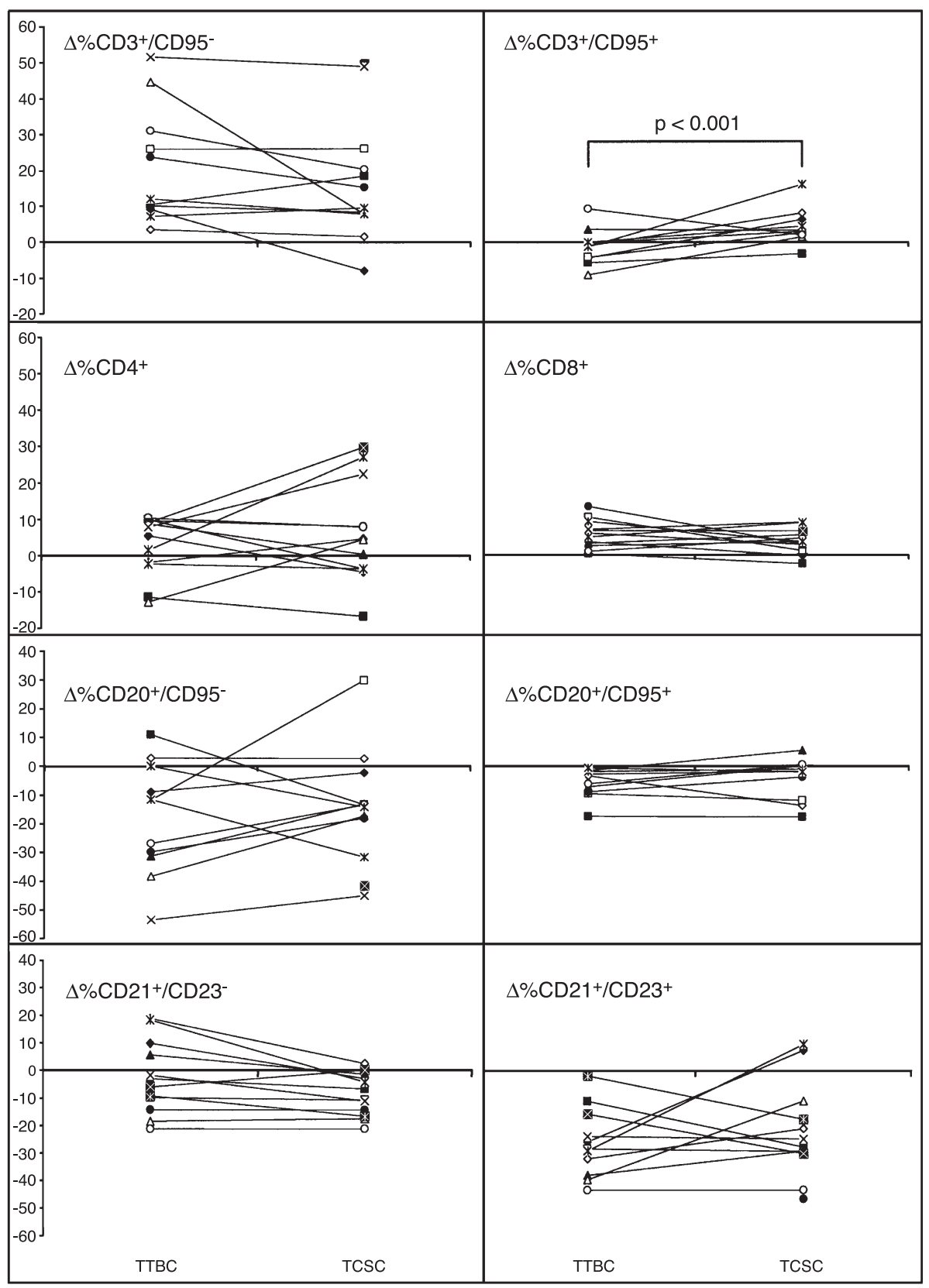

Fig. 5. Distribution of lymphocyte subsets in tonsillar tissue block cultures (TTBCs) and in autologous tonsillar cell suspension cultures (TCSCs) on day 4 of culture relative to day 0 (baseline) was determined by flow cytometry. Values are given as the difference between the percentages of gated cells measured on day 4 and on day 0 from the tissue of the same tonsil. Each tonsil is represented by a different symbol.

TCSC. The proportion of activated $\mathrm{B}$ cells $\left(\mathrm{CD} 21^{+} /\right.$ $\mathrm{CD} 23^{+}$) decreased in TTBCs and TCSCs except in two TCSCs (Fig. 5). These observations indicated that
TTBCs and TCSCs could provide comparable experimental results within the first 4 days of culture, but that TTBCs may be less prone to generate results 
influenced by $\mathrm{T}$ cells activated to susceptibility for apoptosis.

\subsection{Treatment with cyclosporin $A$}

Treatment of TTBCs with CsA at concentrations of 1 or $5 \mathrm{mg} / \mathrm{l}$ did not show significant differences in tissue preservation compared to controls (Fig. 6). At day 4 , the number of follicles and the tissue consistency had decreased and the amount of necrosis increased as seen in untreated TTBCs (total score for each condition 5). By contrast, using CsA at 25 $\mathrm{mg} / \mathrm{l}$ showed less decay of tissue consistency and increase in necrosis, and the density of follicles remained stable (Fig. 6) until day 4 of culture (total score 10).

In general, CsA resulted in an increase of the proportion of $\mathrm{CD}^{+} / \mathrm{CD}^{-} 5^{-}$cells, although with variations of up to $50 \%$. At higher doses, CsA seemed to reduce the proportion of $\mathrm{CD}^{+} / \mathrm{CD} 95^{+}$cells in TTBCs

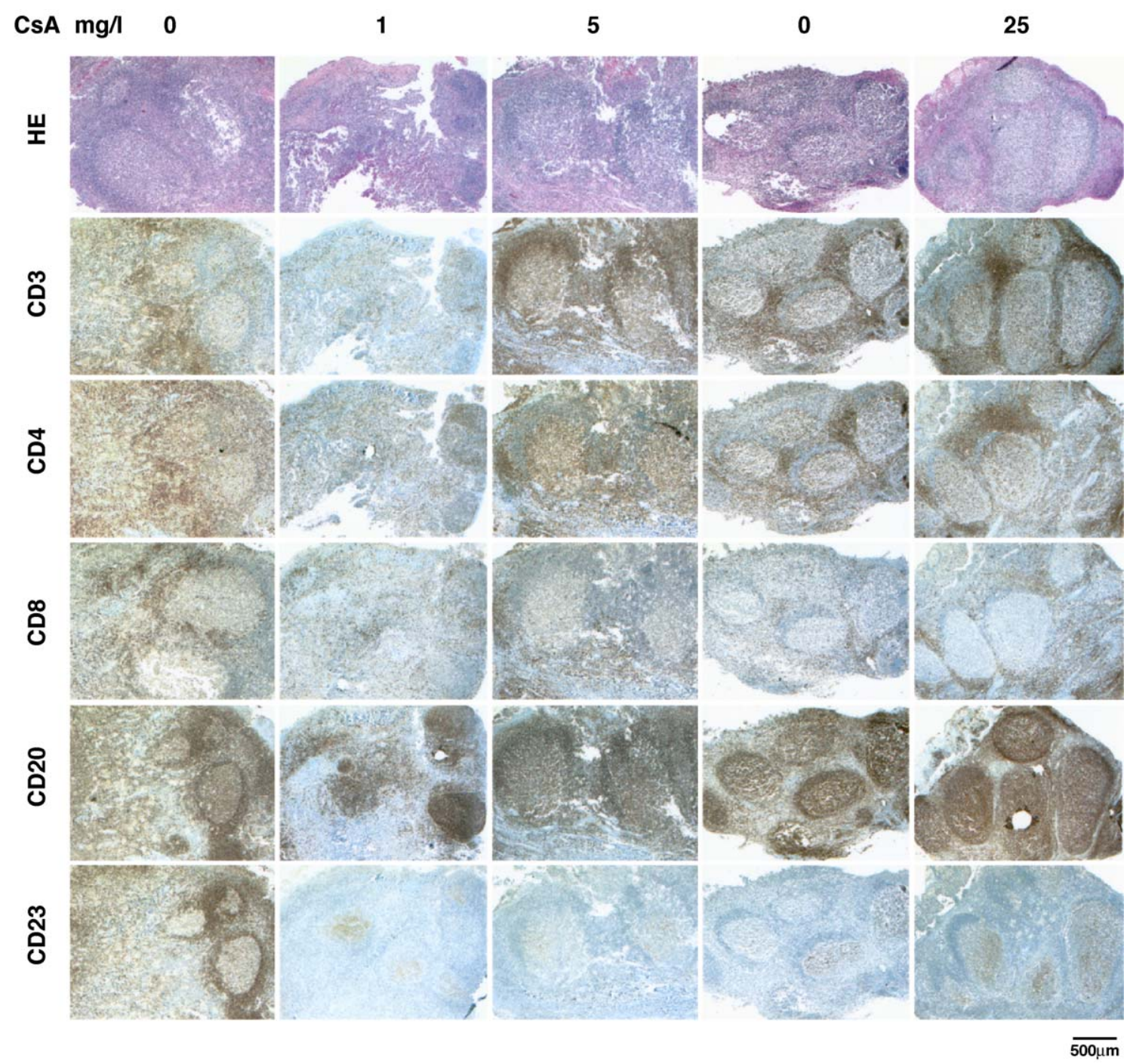

Fig. 6. In situ localisation of lymphocyte subsets in TTBCs on day 2 of culture following no treatment or treatment with CsA. Representative sections from TTBCs from two different donors are shown. CsA denotes cyclosporin A. 
but not in TCSCs (Fig. 7). The range of variation of $\mathrm{CD}^{+}$cells seemed to diminish with increasing concentrations of CsA. The proportion of $\mathrm{CD} 21^{+} / \mathrm{CD} 23^{-}$ cells in TTBCs was either increased or reduced, whereas in TCSCs, it was always reduced. Finally, the percentages of $\mathrm{CD} 21^{+} / \mathrm{CD} 23^{+}$cells were invariably reduced in TTBCs, but not in TCSCs where increases were seen (Fig. 7). Thus, treatment with CsA seemed to prevent the expression of $\mathrm{CD} 95$ by $\mathrm{CD}^{+}$cells and the activation of $\mathrm{CD} 21^{+}$cells in TTBCs. This suggested that CsA treatment of TTBCs could better mimic states of diminished $\mathrm{T}$ cell activation with ensuing activation of B cells as in iatrogenic immunosuppression than did similar treatment of TCSCs.

\subsection{Constitutive expression of cytokine genes}

There were no differences between TTBCs and TCSCs in the constitutive expression of IL-2, IFN- $\gamma$, IL-10, IL-12 and IL-15 (data not shown). By contrast, the constitutive expression levels of IL-1 $\beta$ and IL-6 were higher in TTBCs than in autologous TCSCs

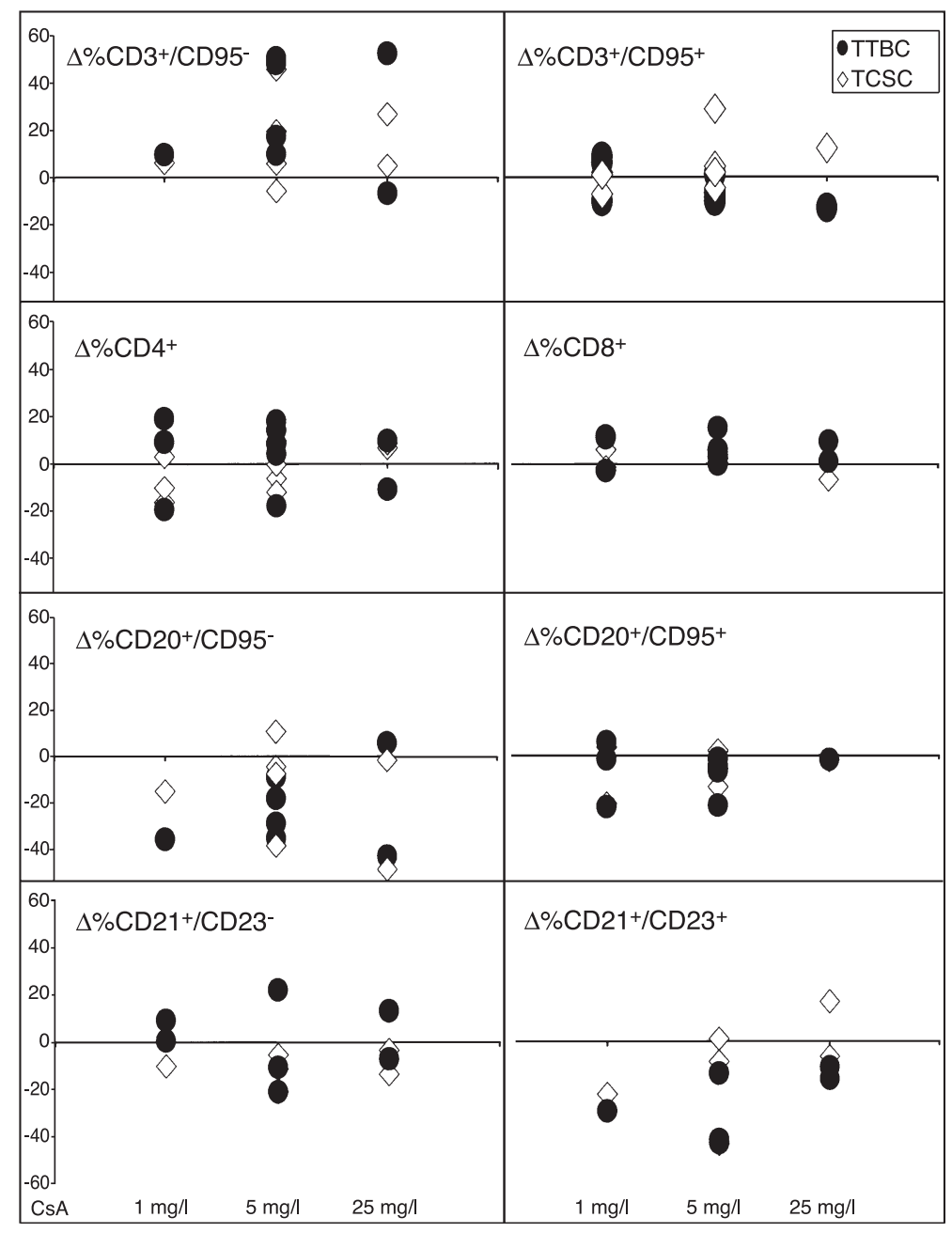

Fig. 7. Distribution of lymphocyte subsets in tonsillar tissue block cultures and autologous tonsillar cell suspension cultures on day 4 of culture with 1,5 or $25 \mathrm{mg} / 1$ cyclosporin A relative to nontreated cultures (baseline) determined by flow cytometry. Values are given as the difference between the percentages of gated cells obtained from cultures treated with cyclosporin A (CsA) and untreated cultures of tonsillar tissues or single-cell suspensions from the same tonsil. TTBC, tonsillar tissue block culture; TSCS, tonsillar cell suspension culture. 


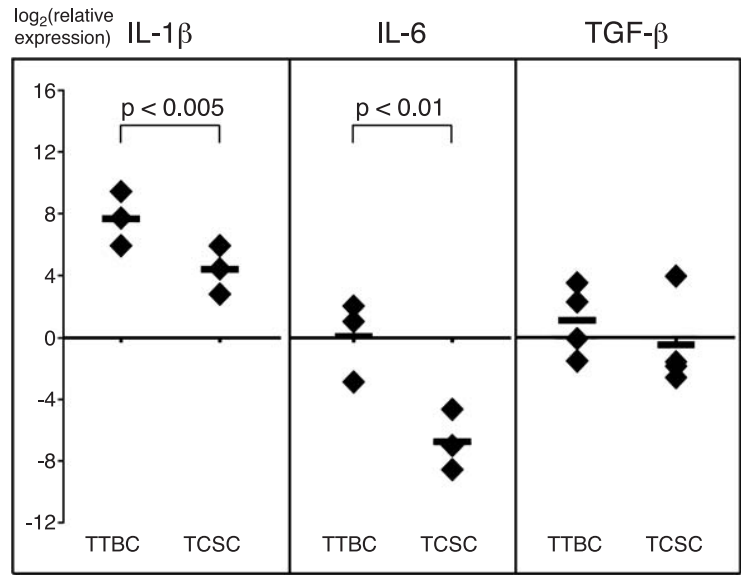

Fig. 8. Cytokine gene expression in tonsillar tissue block cultures versus autologous tonsillar cell suspension cultures. mRNA was extracted from cultures on day 2 and reverse-transcribed. Expression of IL-1 $\beta$, IL- 6 and transforming growth factor (TGF)- $\beta$ was quantified by real-time polymerase chain reaction. Cycle threshold values were normalised to the housekeeping gene hydroxymethylbilane synthase and calibrated on the calibrator sample with CARTA (Bonanomi et al., 2003). The results are expressed as $\pm \log _{2}$ (expression) relative to the calibrator sample. Horizontal bars indicate mean values. TTBC, tonsillar tissue block culture; TSCS, tonsillar cell suspension culture.

( $p<0.005$ and $p<0.01$, respectively), whereas the levels of TGF- $\beta$ in TTBCs and TCSCs were within the same range (Fig. 8). This indicated that relevant differences in cytokine-driven activities exist between immune cells within intact tissue structures and immune cells deprived of their natural habitat.

\section{Discussion}

The evolution of TTBCs with regard to morphological appearance, distributions of lymphocyte subsets, reaction to CsA and cytokine gene expression have been studied for the first time. Lymphoid tissue was well preserved until day 4 of culture. High doses of CsA prevented disintegration of lymphoid follicles. Compared to autologous TCSCs, TTBCs showed less $\mathrm{T}$ cells activated to express CD95 and exhibited contrasting constitutive cytokine gene expression patterns.

Although Yssel's medium seemed to prevent cell decay better until day 3, RPMI 1640 medium was preferred since it did not provoke disintegration of the sponges used to nest the tissue blocks and thus allowed better processing for histology. Our results contrast with those of (Glushakova et al., 1995) who cultured TTBCs for 10-26 days and reported that the key elements of tissue architecture, including welldefined germinal centres, were preserved even into the fourth week of culture. However, immunohistochemical data were not presented. Another study of TTBCs addressing histology, although less systematically than the present study, obtained acceptable viability of cells until day 4 in one experiment and until day 7 in another experiment (Ferro et al., 1993). Studies using human spleen for functional experiments during a period of 3-7 days did not investigate histology (Hoffmann et al., 1995; Skibinski et al., 1997).

During the first 4 days of culture, a similar relative increase of $\mathrm{T}$ cells paralleled by a decrease of B cells was observed in TTBCs and TCSCs. This low survival of B cells was expected based on the great number of naive $B$ cells in lymphoid follicles. Naive B cells die within $48 \mathrm{~h}$ in the absence of specific antigen stimulation (Liu, 1992). This was reflected by the increasing amount of necrosis over time within the follicles seen in the tissue sections (Figs. 1 and 2).

Significantly less frequent and less numeric increases in the proportion of $\mathrm{T}$ cells activated to express CD95 were observed in TTBCs compared to TCSCs. This suggested that T cells in TTBCs experienced fewer stimuli-provoking expression of CD95 and susceptibility to the cell death program than was the case for T cells in TCSCs. One reason could be that cutting the tonsils into pieces results in fewer cell stimulatory events than disruption to obtain single cells. Also, T cells within TTBCs remain sessile, whereas in TCSCs, they are obviously mixed with the cellular components of all the distinct lymphoid tissue areas. Thus, T cells in TCSCs are more likely exposed to foreign and self-antigenic stimuli usually located in different areas of the organ. The smaller range of variation in the frequencies of $\mathrm{CD}^{+} \mathrm{T}$ cells compared to baseline in TTBCs versus TCSCs is in agreement with a more controlled degree of stimulation in TTBCs than in TCSCs. Thus, the study of specified T cell stimulatory events in TTBCs would be expected to be less confounded by cell manipulationinduced in vitro effects and therefore give results closer to reality. 
Treatment of TTBCs with CsA at high doses prevented disintegration of lymphoid follicles. Thus, CsA at these concentrations seemed to penetrate TTBCs in amounts sufficient to exert an effect. A clear-cut dose-related effect of CsA on the distribution of lymphocyte subsets was neither seen in TTBCs nor in TCSCs, indicating that CsA exhibited functional changes rather than numeric changes in immune cells. Indeed, CsA interferes with the inducible transcription of cytokine genes in T cells, B cells and other immune cells (Shaw et al., 1995; Matsuda and Koyasu, 2000; Tajima et al., 2003).

The significantly higher levels of constitutive gene expression for the pro-inflammatory cytokines IL-1 $\beta$ and IL-6 in TTBCs, compared to TCSCs, were remarkable, and notably no differences were found for the cytokines IL-2, IFN- $\gamma$, IL-10, IL-12 and IL-15. Major differences in the spontaneous cytokine secretion profile have been noted between tissue cultures and cell suspension cultures of human spleen (Skibinski et al., 1997). Similar to our findings, the stromal cytokines IL-1 $\beta$, IL-6, IL-8 and IL-11 were detected in supernatants of tissue block cultures at significantly higher concentrations than in supernatants of cell suspension cultures (Skibinski et al., 1997). These differences could be partly attributable to the loss of key cell types while preparing TCSCs, such as stromal or follicular dendritic cells, major sources of these pro-inflammatory cytokines. A more plausible reason could be the disruption of vital cellcell and cell-matrix interactions during preparation of the cell suspensions. Finally, removal of key cells or of important mediators during washing of the cell suspensions could also lead to differences in comparison to TTBCs.

TTBCs differed at least in two remarkable aspects from TCSCs, namely, in a less frequent increase in CD95 expression in T cells, which indicates augmented susceptibility to apoptosis in TCSCs, and in cytokine gene expression. Both aspects may be interconnected and depend on various factors, of which cell-to-cell interaction seems to be a crucial one. For the cross talk between immune cells, the microenvironment of a lymphoid organ is substantial, as can be concluded from the distribution of lymphocyte subsets with different functions to different areas of the organ. Thus, in vitro investigations of immunerelated events, especially those expected to occur in secondary lymphoid organs, using TTBCs may more closely reflect in vivo processes than when using TCSCs. We have documented that TTBCs preserve the organ structure for a limited time. Within the framework of 4 days, they may be more appropriate than TCSCs for the study of immune responses to infectious agents naturally invading the nasopharynx and effects of immunosuppressive compounds on these responses and the promotion of pathologic lymphoproliferation as induced by Epstein-Barr virus. Also, mimicking a state of immunosuppression in ex vivo lymphoid tissue, e.g., using CsA, may be more accurate in TTBCs than in TCSCs. Finally, TTBCs may make it possible to identify anatomically the sites of specific processes and to pinpoint them at the single-cell level, e.g., by employing in situ hybridisation or in situ PCR.

\section{Acknowledgements}

This work was supported by SWISS BRIDGE Foundation, the Cancer League of the Kanton of Zurich, the Swiss National Foundation (grants \#3253982.98 and \#3339-64124.00), the EMDO-Stiftung and the Sassella-Stiftung.

\section{References}

Abbas, A., Lichtman, A., 2003. Cellular and Molecular Immunology. Saunders, Philadelphia, PA.

Au, J.L., Jang, S.H., Wientjes, M.G., 2002. Clinical aspects of drug delivery to tumors. J. Control. Release 78, 81.

Blauvelt, A., Glushakova, S., Margolis, L.B., 2000. HIV-infected human Langerhans cells transmit infection to human lymphoid tissue ex vivo. AIDS 14, 647.

Bonanomi, A., Kojic, D., Giger, B., Rickenbach, Z., Jean-RichardDit-Bressel, L., Berger, C., Niggli, F.K., Nadal, D., 2003. Quantitative cytokine gene expression in human tonsils at excision and during histoculture assessed by standardized and calibrated real-time PCR and novel data processing. J. Immunol. Methods 283, 27.

Bounou, S., Leclerc, J.E., Tremblay, M.J., 2002. Presence of host ICAM-1 in laboratory and clinical strains of human immunodeficiency virus type 1 increases virus infectivity and CD4(+)-Tcell depletion in human lymphoid tissue, a major site of replication in vivo. J. Virol. 76, 1004.

Collins, K.B., Patterson, B.K., Naus, G.J., Landers, D.V., Gupta, P., 2000. Development of an in vitro organ culture model to study transmission of HIV-1 in the female genital tract. Nat. Med. 6, 475. 
Ferro, L.M., Weedon, H.M., Flego, L.R., Beroukas, D., Zola, H., 1993. An organ fragment culture model to study lymphocyte activation in human lymphoid tissue. Immunobiology 188, 51.

Glushakova, S., Baibakov, B., Margolis, L.B., Zimmerberg, J., 1995. Infection of human tonsil histocultures: a model for HIV pathogenesis. Nat. Med. 1, 1320.

Grivel, J.C., Ito, Y., Faga, G., Santoro, F., Shaheen, F., Malnati, M.S., Fitzgerald, W., Lusso, P., Margolis, L., 2001. Suppression of CCR5-but not CXCR4 - tropic HIV-1 in lymphoid tissue by human herpesvirus 6 . Nat. Med. 7, 1232.

Grivel, J.C., Santoro, F., Chen, S., Faga, G., Malnati, M.S., Ito, Y., Margolis, L., Lusso, P., 2003. Pathogenic effects of human herpesvirus 6 in human lymphoid tissue ex vivo. J. Virol. 77, 8280.

Hoffmann, P., Skibinski, G., James, K., 1995. Organ culture of human lymphoid tissue: I. Characteristics of the system. J. Immunol. Methods 179, 37.

Jenkinson, E.J., Franchi, L.L., Kingston, R., Owen, J.J., 1982. Effect of deoxyguanosine on lymphopoiesis in the developing thymus rudiment in vitro: application in the production of chimeric thymus rudiments. Eur. J. Immunol. 12, 583.

Liu, Y.-J.e.a., 1992. Germinal centres in T-cell-dependent antibody responses. Immunol. Today 13, 17.

Matsuda, S., Koyasu, S., 2000. Mechanisms of action of cyclosporine. Immunopharmacology 47, 119.
Penn, M.L., Myers, M., Eckstein, D.A., Liegler, T.J., Hayden, M., Mammano, F., Clavel, F., Deeks, S.G., Grant, R.M., Goldsmith, M.A., 2001. Primary and recombinant HIV type 1 strains resistant to protease inhibitors are pathogenic in mature human lymphoid tissues. AIDS Res. Hum. Retrovir. 17, 517.

Shaw, K.T., Ho, A.M., Raghavan, A., Kim, J., Jain, J., Park, J., Sharma, S., Rao, A., Hogan, P.G., 1995. Immunosuppressive drugs prevent a rapid dephosphorylation of transcription factor NFAT1 in stimulated immune cells. Proc. Natl. Acad. Sci. U. S. A. 92, 11205.

Skibinski, G., James, K., 1997. The use of tissue slices in immunological investigations. Arch. Immunol. Ther. Exp. (Warsz) 45, 411.

Skibinski, G., Hoffmann, P., Radbruch, A., James, K., 1997. Organ culture of human lymphoid tissue: II. Marked differences in cytokine production and proliferation between slice and suspension cultures of human spleen. J. Immunol. Methods 205, 115.

Tajima, K., Amakawa, R., Ito, T., Miyaji, M., Takebayashi, M., Fukuhara, S., 2003. Immunomodulatory effects of cyclosporin A on human peripheral blood dendritic cell subsets. Immunology 108,321 . 